A COMPARISON OF THE EXPLANATORY PRACTICES OF MENTALISM AND BEHAVIOR ANALYSIS

UMA COMPARIÇÃO DAS PRÁTICAS EXPLICATIVAS DO MENTALISMO E DA ANÁLISE DO COMPORTAMENTO

\author{
JAY MOORE
}

UNIVERSITY OF WISCONSIN-MILWAUKEE, USA

\begin{abstract}
RESUMO
O mentalismo é uma orientação à explicação causal do comportamento em que as causas são inferidas como estruturas não observáveis, pertencentes a domínios não comportamentais. Tipicamente, essas estruturas são tidas como subjacentes ao comportamento, e o domínio em questão é o da "mente". Em alguns casos, com algumas exceções, o mentalismo dialoga com a psicologia tradicional ou com o dualismo de substância. Os argumentos em prol das explicações mentais subscritos aos níveis teórico e conceitual não levam em consideração a fonte das referidas explicações. A análise do comportamento se opõe ao mentalismo por razões pragmáticas, ao invés de ontológicas: o mentalismo impede uma análise do comportamento genuína, que possa contribuir no âmbito da previsão e do controle, por confundir os cientistas ao induzi-los a aceitar explicações inefetivas acerca do seu objeto de estudo.

Palavras-chave: análise do comportamento, explicação, mentalismo, método científico, comportamento verbal.
\end{abstract}

\begin{abstract}
Mentalism is an orientation to the causal explanation of behavior in which the causes are inferred to be unobservable structures from a non-behavioral domain. Typically, the structures are held to underlie behavior, and the domain is that of "mind." In some but not all cases, mentalism subscribes to traditional psychophysical or substance dualism. Arguments that mental explanations are at the theoretical or conceptual level fail to consider the source of the explanation in question. Behavior analysts oppose mentalism on pragmatic, rather than ontological grounds: mentalism impedes a genuine science of behavior contributing to prediction and control by misleading scientists and inducing them to accept ineffective explanations of their subject matter.

Key words: behavior analysis, explanation, mentalism, scientific method, theory, verbal behavior.
\end{abstract}

This article is taken from material I developed over the years to help in my own teaching on the explanatory practices of mentalism and behavior analysis. I offer it here in the hope others will find it useful. In keeping with the instructional goal of the article, references are at a minimum. In addition, both the language and the arguments are more informal than in other articles. If I have fallen short in the execution, I apologize and ask for the reader's tolerance. I can only say the contingencies haven't finished with me yet. Correspondence concerning the article should be addressed to the author at jcm@uwm.edu, or at his home address: 1861 E. Fox Lane; Fox Point, WI 53217; USA. 


\section{A COMPARISON OF THE EXPLANATORY PRACTICES OF MENTALISM AND BEHAVIOR ANALYSIS}

Mentalism is the dominant orientation in contemporary psychology to the causal explanation of behavior. Mentalism can take many forms, from (a) Freudian personality development and psychopathology; to (b) contemporary cognitive, information processing psychology; to (c) contemporary social psychology; to (d) contemporary medical model views of behavioral pathology as represented in DSM-V. The present article reviews the principal features of mentalism and compares its explanatory practices with those of behavior analysis. Because of the great range of mentalistic positions, the present review is necessarily abstract in many instances, but it can be applied in particular cases with suitable modification.

\section{A DEFINITION OF MENTALISM}

We speak of an explanation as mentalistic when it involves the following features:

- That the proper goal of psychological science is to postulate a set of acts, states, mechanisms, processes, entities, and structures whose functional properties make possible whatever form of behavior is of interest. Henceforth, we use simply one term: structures.

- That these structures are part of the intrinsic psychological make-up of the organism. An organism does not acquire them during its lifetime through experience with the environment in any substantial way. For example, they may be developmental or evolutionary.

- Physiological measures provide neural correlates and evidence of the underlying mental structures, but don't define them. The structures are defined by their functional properties, such as capacities, contents, processing times, and so forth, rather than their physical realization or observable expression. The structures afford competence, which makes the observed behavior possible in whatever situation the organism finds itself. Finally, the behaving organism is not necessarily consciously aware of the operation of these mental structures.

- That the structures are inferred and underlying, rather than observable.

- That the structures and their properties may be regarded as causal, and the specification of the structures, their functional properties, and the architecture of the system as a whole, even at the conceptual level, constitutes the causal explanation of behavior.

The presumed locus of these structures varies with different versions of mentalism. In some versions, the structures are inferred to be inside the organism in some sense, perhaps as manifestations of cortical structures. In other cases, they are inferred to be at the conceptual level, and it is no more meaningful to ask where the locus is of some inferred structure or property than it is to ask where the locus is of the horsepower of an internal combustion engine. However, various forms of observable data (i.e., evidence) are taken to support this inferential project, ranging from behavioral (reaction time, eye tracking, ratiocination, perceptual judgments) to physiological (fMRI, PET, action potentials and synaptic mechanisms in cortical structures or pathways). In this regard, observable behavior is relevant because it provides evidence to support inferences about the causal properties of mental structures, rather than because it is a subject matter in its own right.

Again, mentalism implicitly assumes that an organism's psychological make-up includes a domain beyond the one in which behavior takes place. The domain of an explanation is of concern when its analytic concepts and its methods of observation are unrelated to the behavioral facts for which they are said to account. Representative descriptors for this non-behavioral domain are mental, cognitive, subjective, spiritual, psychic, conceptual, hypothetical - in short, the domain of "mind." Different versions of mentalism emphasize different terms related to this inferred domain.

Mentalism also entails a commitment to the inferred mental structures from the non-behavioral domain as causally effective antecedents. Observable environmental events, variables, and relations are also antecedents for behavior, but for mentalism they are not causes of behavior. At best they are only triggers for the underlying causal structures. First, the organism and its behavior are assumed to be in direct contact with only the mental structures or their outputs, rather than environmental factors. How can something with which the organism is not in direct contact be considered causal? Second, behavior is richer and more flexible than an account in terms of observable environmental factors allows. Consider the sequential organization of behavior as an example. Such behavior does not consist of a mere chain of concatenated reflexes. Rather, sequential behavior is richer and more flexible. It follows that the independent variables must be at least as rich and flexible as the dependent variable, meaning that an explanation in terms of the causal properties of underlying mental structures is necessary.

The functional properties of the causal mental structures differ for versions of mentalism, and typically range from initiating to mediating. By initiating we mean that the structures themselves are held to be the source of the behavior, such that no cause beyond the structures is necessary to explain the behavior. By mediating we mean that observable external stimuli activate or trigger one or more unobservable intervening or mediating structures that are held to be causally connected in some complex but systematic way to an ensuing observable response. Often mental explanations resemble the $\mathrm{S}-\mathrm{O}-\mathrm{R}$ approach that is found in the history of behaviorism, where the $\mathrm{O}$ stands for explicitly non-behavioral, "organismsic" variables that are inferred to mediate the relation between $S$ and $R$ and provide the desired richness and flexibility. However, mentalism 
argues it is vastly superior in explanatory scope to behaviorism because its mental mediators are vastly superior to those in behaviorism.

In any event, the properties of these causal mental structures cannot be characterized in the same terms, and do not function according to the same principles as observable events, variables, and relations in the environment. Sometimes the structures are assumed to either have or to produce a content on which other structures or processes operate, in the sense of the flowchart of a computer program, but again their contributions are not materially and uniquely determined by an organism's experience. Mentalism applies whether the domain and its causal structures are said to be materialistic or dualistic (i.e., metaphysical or substance dualism).

Recognizing that different forms of mentalism conceive of the causal properties of underlying structures in different ways, we can see that for mentalism, a causal explanation of behavior is incomplete at best and defective at worst if it deploys only concepts from the observable behavioral domain, such as observable environmental events, variables, and relations. To be sure, an organism experiences observable environmental events, variables, and relations during its lifetime, but for mentalism these environmental factors are only matters of performance. They are not causes, and the theoretical understanding and explanation of behavior appropriate to science cannot be achieved in terms of these factors.

Mentalists often argue that their point of view follows from the history of science. According to mentalists, progress in science has always been achieved by inferring theoretically rich analytic and explanatory concepts that are unobservable, rather than by limiting analyses and explanations to events, variables, and relations that are observable. Representative examples are atoms, electrons, cell theory, germ theory of disease, receptor sites. None of these explanatory concepts were directly observed at the time they were first inferred. The mentalist argument is they all illustrate why science should not be restricted to observable events, variables, and relations. Prediction and if necessary control will naturally follow as a consequence of inferring the underlying, unobservable structures that are the genuine concern of science, but prediction and control are matters of engineering. The various forms of mentalism such as cognitive psychology simply do the same as all genuine theoretically oriented sciences and infer these underlying, unobservable phenomena, then try to demonstrate the validity of the inferences through research.

To be sure, mentalism endorses the position that science seeks explanations. For mentalism, explanations are statements that provide a basis for a theoretical understanding of the causal mechanisms or principles postulated to underlie the events we observe. A longstanding epistemological assumption of mentalism is that scientific explanations may begin but they do not end with our observations. Rather, scientific explanations must appeal to underlying factors that are part of a domain that differs from the observable domain. Again, the mentalist argument is that the history of science suggests science has always progressed by looking beyond or behind what we observe to make statements about underlying causal factors that have not been directly observed. At best the study of observable factors in an event is useful to the extent it provides a basis for supporting inferences about those underlying factors as the true causes of an event. Thus, in the case of behavior and such other psychological phenomena as learning, perception, and memory, the true causes are the underlying structures that yield the capability for behavior in particular circumstances and provide competence. To study the relation between observable factors in an event is only to describe performance and how the event came about, not explain why it came about.

How then are we to reconcile the view that the underlying mental structures necessary for explanation are unobservable with the view that science deals only with publicly observable phenomena? For mentalism, the problem is not as severe as it appears. Science often deals with things it cannot directly see or measure. For mentalism, the unobservable mental structures may be operationally defined as hypothetical constructs. Science may then deal with them indirectly, at the conceptual level through what are taken to be their manifestations, and thereby generate true explanations. On this view, researchers and theorists should be free to postulate whatever underlying mental structures and so on are suitable to explain the observation in question, and then gather data that address the adequacy of their postulations. For mentalists, behaviorism seeks explanations limited to observables, and is surely inadequate. Mentalism is richer and preferable because it admits explanatory concepts that are richer and preferable, precisely because they are not restricted to observables.

As suggested above, mentalists contrast their position directly with behaviorism. According to mentalists, behavioral explanations are expressed solely in terms of observable environmental events, variables, and $\mathrm{S}-\mathrm{R}$ relations. Consequently, behavioral explanations focus solely on describing performance-_What happened?" Mentalists hold that such explanations are incomplete at best because they don't specify the underlying, unobservable causal structures responsible for the performance. Rather, appropriate explanations need to answer questions of "Why did it happen?" in the sense of "What underlying structure is responsible?" The assumption is that if the underlying theoretical structure hasn't been postulated, the behavior hasn't been truly explained. Therefore, behaviorism can't possibly be regarded as generating genuinely theoretical, explanatory knowledge, and can't possibly be regarded as genuinely scientific.

According to mentalism, everyone knows humans have minds, which are unobservable. In a general sense, mind may be understood as the set of mental structures that mediate behavior in particular circumstances. As the 
saying goes, mind is what the brain does. The functional properties of these mental structures are innate and not markedly influenced by experience. If they were, they would be behavioral and descriptive, rather than mental and genuinely explanatory. Any account of human behavior that claims to be an explanation and that doesn't include the role of unobservable theoretical structures such as the mind cannot possibly be adequate.

Accounts of the behavior of non-humans, such as laboratory rats and pigeons, or of humans with developmental disabilities, in terms of unobservable theoretical structures are not necessarily problematic. However, accounts of the behavior of typically developing or developed humans must surely appeal to their minds. Extensions of accounts pertaining to human society and culture must also surely appeal to minds and underlying mental structures.

In sum, mentalism argues that mind is necessary for psychological explanations, and mind can be dealt with in a scientifically acceptable way.

\section{BEHAVIOR ANALYTIC VIEW OF SCIENCE}

How then does behavior analysis stand with respect to these many matters? Clearly, one of the major differences between mentalism and behavior analysis turns on the different conceptions of the causal explanation of behavior.

We start by suggesting that for behavior analysis, science is in large measure the operant behavior of scientists, along with (a) the artifacts associated with the origin and the execution of their behavior and (b) the artifacts produced by their behavior. Accordingly, scientific behavior ranges from ongoing research activities in the laboratory to talking and writing about those activities. The artifacts associated with the origin and the execution of their behavior range from the scientific apparatus we use in those research activities, such as test tubes, scales, microscopes, and so on, to the established data base and codified methods of scientific procedures. The artifacts produced by their behavior range from new scientific apparatus, such as new scales and microscopes, to extensions of published research, refinements of theories, alternative explanations, and new interpretations.

Moreover, the reinforcers for the operant behavior of science fall on a continuum. At one end is the prediction and control of natural events. At this end we are concerned with shaping nature as on an anvil and deriving outcomes that are reinforcing for us, through our direct, practical action. At the other end is the discovery of uniformities, the ordering of confusing data, and the resolution of puzzlement. At this end we are concerned with the generalized and abstract verbal products of science, such as theories, explanations, and interpretations that transcend particular instances of prediction and control. These abstract products are derived from more particular endeavors, and they become progressively more abstract as science and technology progress.

Primitive science presumably began with primitive technologies: making clay pots, making hammers and swords, making clothing, making houses, making transportation devices, domesticating animals, selectively breeding plants and animals. Cultures then developed rules for transmitting acquired knowledge about these technologies to future generations. The rules became formalized as sources of discriminative control.

Over time, the rules became more generalized and abstract, with increased degrees of freedom for their application - different kinds of clay for pots, different kinds of metals for hammers and swords, different sources of material for clothing, different ways to domesticate animals. The important point is that the verbal behavior of science falls on a pragmatic continuum ranging from (a) rules of craftsmen, to (b) functional relations, to (c) higher order analytic and explanatory concepts, to (d) theories, laws, explanations, and interpretations. At one end of the continuum, the principal concern is direct, practical, effective action in particular cases. At the other end, the principal concern is tacting order and uniformities at an abstract, generalized level, based on organizations of data. Theories and explanations may be understood as derived and extended from a foundation of functional relations. The mere accumulation of results is no more valuable as a theory than a heap of stones is valuable as a house (e.g., Poincaré). Data become useful when organized, so that they can inform outcomes.

One important concern here is the nature of the contingencies that influence scientific behavior. To what extent is scientific behavior influenced by contingencies arising from (a) operations and contacts with data that result in effective action with respect to nature-such as prediction and control, as opposed to contingencies arising from (b) social and cultural traditions, (c) mischievous linguistic processes sometimes called reification, and (d) inappropriate metaphors?

Another way to assess the nature of the contingencies that influence scientific behavior is to ask about the outcomes to which the scientific product contributes. Do its outcomes lie a pragmatic continuum ranging from prediction and control of particular events at one end to the discovery of uniformities, the ordering of confusing data, the resolution of puzzlement at the other end? Behavior analysis endorses any of these types of contributions. Alternatively, are its outcomes a matter of conforming to statements of revelation and authority, derived from a supposed domain beyond the natural world and with minimal regard to the outcome of interactions with the natural world? For behavior analysis, mentalism is committed to this latter orientation, and the explanatory practices it promotes are problematic.

An important feature of the above view is that for behavior analysis, scientific behavior is progressive and 
continuous rather than dichotomous. That is, the systematic positions of such great scientists and theoreticians as Galileo, Newton, Darwin, Watson and Crick, and Hawking grew from observational data, either their own or those of others. One type of scientific knowledge is not conceived of as a mere technology, concerned with application or engineering, and another type as a theoretical understanding, unconcerned with application and mutually exclusive from the first type. The first type is not conceived of as a rather pedestrian endeavor, and the second type as intellectually superior and therefore more deserving of esteem and recognition. Finally, behavior analysis is not conceived of as a to-bedisparaged instance of the first type, and mentalism as a to-be-revered instance of the second type. For sure, different forms of scientific activity may be found at different loci on the continuum, but an important consideration is that the forms are related, rather than dichotomous. To distinguish the forms as does mentalism betrays a metaphysics and an epistemology that depart from naturalistic concerns and an understanding of the human behavior that produced those forms.

\section{IMPLICATION \#1: WHY DO SCIENTISTS DO SCIENCE?}

Why then do scientists do science? For behavior analysis, doing science is occasioned by particular antecedent circumstances, and maintained by particular outcomes. Sidman (1960) identified several reasons why scientists conduct scientific research: (a) to evaluate hypotheses; (b) to indulge the investigator's curiosity about nature; (c) to try out a new method or technique; (d) to establish the existence of a phenomenon; and (e) to explore the (boundary) conditions under which a phenomenon occurs. Note that some instances of science may well test hypotheses, but not all science need do so. Thus, research is activity that produces generalizable knowledge. The ultimate aim is to create generalized verbal $\mathrm{S}^{\mathrm{D}} \mathrm{S}$ for effective interaction with nature, even if the verbal products are abstract.

IMPLICATION \#2: RESEARCH METHODS

Research methods in behavior analysis are concerned with identifying classes of manipulations that promote direct, effective action. These methods isolate those manipulations and their effects through various techniques (discrimination and reversal, probes, multiple baselines, control conditions, etc.) that rule out alternative or rival possibilities. The extent to which various antecedent circumstances or characteristics of the population are relevant are then incorporated as necessary, for example, to identify class boundaries.

In contrast, research methods in traditional psychology are based on inferential statistics and sampling techniques. At issue is whether a particular observation is considered to be the metaphysical effect of the manipulation in question, as opposed to simply a random sampling error from a population of outcomes. Pragmatic considerations, such as the clinical as opposed to statistical significance of the effect, are not ordinarily involved.

\section{IMPLICATION \#3: DEMARCATION OF SCIENCE FROM NON-SCIENCE}

For behavior analysts, science is concerned with the pragmatic continuum above in the domain of the natural world, and it may be demarcated from non-science. Nontechnical statements suggest that science (a) is guided by natural law, (b) explains events in terms of natural law, (c) formulates explanations that are testable against observations, (d) offers explanations that are tentative and provisional, and (e) offers explanations that are potentially falsifiable, is to be concerned with the sources of control over scientific verbal behavior that are found in the natural world. Non-science is concerned with revelation and authority derived from a supposed domain beyond the natural world. Note that demarcation doesn't necessarily turn on directly observed or directly manipulated vs not. Of course, we can ask for a scientific account of why individuals make fanciful, non-scientific statements.

\section{IMPLICATION \#4: CRITERIA FOR EMPIRICALLY BASED PRACTICE}

Criteria for empirically based practice at the level of a well-established treatment or therapeutic intervention typically include (a) at least two demonstrations of effectiveness, or a series of single-case designs; (b) by at least two different experimenters; (c) using a documented (e.g., via a manual) intervention with suitable independent and dependent variables; and (d) following a suitable experimental design, with controls for purposes of comparison. In traditional psychology, these criteria are held to be met through a randomized clinical trial, with a group design, and evaluation of results by a test of statistical inference. Recently, a large series of single-case design experiments that demonstrate efficacy with good experimental design and results comparable to another established treatment has also been taken to be satisfactory. These criteria aren't stated in a way that is entirely consistent with a radical behaviorist orientation. Nonetheless, at least we see the concern with the reliability and validity of scientific verbal behavior in terms of the sources of control, much as behavior analysis suggests.

\section{SUMMARY AND CONCLUSIONS}

We have seen that mentalism claims that behavior analysis deals only with observable $\mathrm{S}-\mathrm{R}$ events and relations, whereas mentalism deals with underlying, unobservable theoretical structures. Consequently, mentalism argues that it is scientifically superior. Again, this claim is complex. For example, behavior analysis recognizes private behavioral events, which by definition are not publicly observable. Some of these events are verbal, as in thinking and problem solving. The important 
consideration here is that although these events are private, they are functionally related to environmental circumstances in the actor's life, rather than innate in the same way that mental structures are said to be. In this way, behavior analysis does recognize significant unobservable independent variables in an explanation of behavior. As a result, the claims of mentalism are wide of the mark and uninformed.

As important as a discussion of observable vs unobservable independent variables may be, perhaps an even more important distinction between mentalism and behavior analysis turns on their respective conceptions of verbal behavior. For mentalism, verbal behavior is a referential, symbolic process. In this regard, words are symbols that have meaning. The meaning is a matter of what the words refer to. In some cases, the referent is publicly observable. In other cases, the referent is unobservable - a mental entity. For mentalism, in the case of psychology the mental referent is often some theoretical construct in the mind of the scientist, which then needs to be operationally defined so as to achieve agreement and avoid the pitfalls of introspective approaches. Humans are conceived to be symbol using organisms, and the whole approach is said to follow from these assumptions.

In contrast, behavior analysis regards verbal behavior as a form of operant behavior, amenable to analysis in terms of contingencies. The contingencies may be complex, but the analysis remains at the level of contingencies. It makes no more sense to say that a term or concept is a symbol that refers to something in the mind of the scientist than it does to say that stepping on the brake of a car is a symbol that refers to stopping in the mind of the driver. Representations and other features of mentalism are simply not involved. To attribute verbal behavior to symbol using and referential processes inextricably clouds the analysis. As we have seen, the central issues are the nature of the stimulus control and the nature of the reinforcement for the operant behavior called scientific. Mentalism often reifies concepts from our everyday language. Mentalism further assumes that the concepts so reified represent some sort of discrete entity or mental process with scientific relevance, even though the entity is in another domain.

Behavior analysis suggests a different way to approach these matters. For behavior analysis, the verbal process called abstraction is behavioral. Abstraction concerns stimulus control arising from one restricted aspect of the antecedent setting. No assumptions are made that (a) the named aspect represents some structure from another domain, (b) science is concerned with this structure as underlying observable events, and (c) observations stand as evidence for the existence of the structure. To so assume leads science down the garden path of ineffective interactions with the world.

Behavior analysis is ultimately concerned about mentalism on pragmatic rather than ontological grounds. More specifically, behavior analysis argues that mentalism obscures and indeed actively impedes the search for important details about the genuinely relevant relations between behavior and environment, it allays curiosity by getting us to accept fanciful "explanatory fictions" as causes, it misrepresents the facts to be accounted for, and it gives us false assurances about the state of our knowledge. Consequently, behavior analysis argues that mentalism actually interferes with effective prediction, control, and explanation of behavior, despite mentalist claims to the contrary. The conception of mental variables implies that they and the behavior they cause arise and operate relatively independently of environmental circumstances, and we can do nothing to promote beneficial forms of behavior or replace problematic forms, surely not an optimistic stance for a life science. For behavior analysis, genuine answers concerning the causes and explanation of behavior may be found in the analysis of contingencies at the level of phylogeny, ontogeny, and culture.

Key terms and concepts: behavior analysis, explanation, hypothetical constructs, mental structures, mentalism, scientific method, theory, verbal behavior.

\section{REFERENCES}

Sidman, M. (1960). Tactics of scientific research. New York: Free Press.

Submitted: 03/28/2018 Accepted: 04/21/2018 